\title{
Siofra Pierse, Voltaire historiographer: narrative paradigms
}

\section{Gianni lotti}

\section{(2) OpenEdition}

1 Journals

\section{Edizione digitale}

URL: http://journals.openedition.org/studifrancesi/7942

DOI: ERREUR PDO dans /localdata/www-bin/Core/Core/Db/Db.class.php L.34 : SQLSTATE[HYO00]

[2006] MySQL server has gone away

ISSN: 2421-5856

\section{Editore}

Rosenberg \& Sellier

\section{Edizione cartacea}

Data di pubblicazione: 1 juillet 2009

Paginazione: 402-403

ISSN: 0039-2944

\section{Notizia bibliografica digitale}

Gianni lotti, «Siofra Pierse, Voltaire historiographer: narrative paradigms», Studi Francesi [Online], 158 (LIII | II) | 2009, online dal 30 novembre 2015, consultato il 07 janvier 2021. URL: http://

journals.openedition.org/studifrancesi/7942 ; DOI: https://doi.org/10.4000/studifrancesi.7942

Questo documento è stato generato automaticamente il 7 janvier 2021.

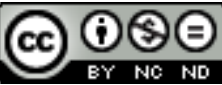

Studi Francesi è distribuita con Licenza Creative Commons Attribuzione - Non commerciale - Non opere derivate 4.0 Internazionale. 


\title{
Siofra Pierse, Voltaire historiographer: narrative paradigms
}

\author{
Gianni lotti
}

\section{NOTIZIA}

SIOFRA PIERSE, Voltaire historiographer: narrative paradigms, Oxford, Voltaire Foundation, 2008 («SVEC $2008: 5 »)$, pp. xiii-283.

1 A partire dalla pubblicazione, avvenuta nel 1958, di due lavori con lo stesso titolo che sono rimasti in seguito testi di riferimento - Voltaire historian di John Henry Brumfitt e Voltaire storico di Furio Diaz - gli studi sull'opera storica di Voltaire hanno registrato una fortuna crescente. Ma la maggior parte di essi ha continuato a privilegiare soprattutto la dimensione ideologica, mentre questo volume di Síofra Pierse, estremamente solido e ben documentato, secondo la tradizione degli «SVEC», è meritoriamente incentrato sul problema della scrittura voltairiana della storia: modalità discorsive, molteplicità delle voci d'autore, appelli al destinatario, strategie polemiche, enjeux propagandistici costituiscono gli oggetti privilegiati dell'analisi. Dopo aver enucleato i sei «cornerstones» (p. 16) dell'opera storica di Voltaire (messa al bando della fantasia e dell'inverosimile; distanza prospettica dai fatti; ricorso rigoroso alle fonti; uso sapiente della forma narrativa; competenza non asfitticamente specialistica dello storico; ideale sintetico opposto al carattere compilativo delle cronache tradizionali), la studiosa dedica la prima parte del lavoro («Narrative») alla disamina della voce autoriale. Più precisamente vengono individuate tre istanze dominanti all'interno dell'enunciazione "contrappuntistica" di Voltaire - lo storiografo, l'autore e il lettore - che si mescolano, si sovrappongono e si alternano animando un discorso nettamente distaccato, per complessità d'impianto e originalità di prospettiva, dalla produzione coeva. A una serie di manifestazioni della funzione-destinatore che vanno dalle tecniche di pseudonimato alle varie forme di "intrusione d'autore" corrisponde, in direzione della funzione-destinatario, il dialogo intra- ed extra-diegetico continuamente intrattenuto con il pubblico più avvertito, con qualche singolo lettore 
privilegiato (come Madame du Châtelet), o con il lettore ideale i cui tratti sfumano in quelli della posterità, nel contesto d'una concezione della storia concepita quale strumento pratico di conoscenza del presente e di progettazione del futuro.

2 Alla descrizione delle modalità dell'enunciazione, la seconda parte del lavoro («Story») fa succedere quella dell'enunciato. Dapprima viene preso in considerazione il fenomeno tipico della digressione voltairiana con i suoi temi obbligati (la visione negativa della guerra, la fragilità umana, il fanatismo religioso); quindi si insiste sulla fondamentale distinzione fra héros e grand homme nella quale è riflesso il passaggio epocale dal primato dei valori guerreschi a quelli umanitari di pace, giustizia e tolleranza. Certo, nota Pierse, dietro il dispiegamento d'una tale concezione s'intravede l'intento del patriarca di Ferney, benefattore e paladino della giustizia, di forgiarsi la propria immagine di grand'uomo. Ma ciò può avvenire precisamente in quanto la grandezza è ormai concepita come qualità non più istituzionalmente limitata a re e a potenti: secondo la nuova morale voltairiana, gli eroi tradizionali, i soldati vittoriosi non sono in fondo che dei saccageurs de provinces; mentre i grandi uomini - e le grandi donne - si distinguono per la vastità del loro pensiero e l'entità dell'apporto alla causa dell'umanità.

3 La terza parte dello studio («Truth»), infine, si concentra sui rapporti tra histoire e fable. Se da una parte Voltaire si sforza di sganciare la storia dalla narrazione fantasiosa, dall'altra il suo scetticismo lo porta a mettere in dubbio la totale verificabilità del fatto storico e a ricercarne problematicamente la consistenza ben oltre la tradizionale identificazione con una serie di date, monarchi e battaglie. Da qui, per lo storico philosophe, il conseguente disprezzo nei confronti dei dettagli e la giustificazione - o piuttosto la rivendicazione - della "parzialità necessaria" d'un racconto storico finalizzato all'educazione intellettuale degli uomini e al progresso dello spirito.

Al lavoro di Síofra Pierse vanno senz'altro riconosciute notevoli qualità d'informazione, di organicità e di penetrazione anche se, forse, da un libro nel cui titolo compare l'espressione "paradigmi narrativi" ci si poteva aspettare una maggiore attenzione agli effetti più propriamente letterari della scrittura voltairiana. Le opere storiche di Voltaire, giova ribadirlo, sono opere d'artista in senso classico. Spesso, malgrado l'ostentato rigetto del romanesque, del merveilleux e della finzione, l'autore si lascia felicemente prendere la mano dal narratore o dal drammaturgo, e la sollecitazione immediatamente emotiva del lettore è tutt'altro che estranea ai suoi mezzi e ai suoi obiettivi. Come si legge in una lettera di Voltaire a Hénault del gennaio 1752 a proposito del Siècle: «En un mot, j'ai voulu émouvoir, même dans l'histoire». Di fatto l'analisi di Pierse, i cui principi metodologici si rifanno ad autori come Barthes, Foucault e Ricoeur, privilegia pressoché esclusivamente l'articolazione formale e "politica" del Discorso lasciando un po' troppo in ombra fattori essenziali di ciò che chiamiamo la letterarietà quali la definizione psicologica dei personaggi, la drammatizzazione delle situazioni, la tentazione del comico e del paradossale. Certo, Voltaire punta prioritariamente a stimolare il senso critico dei suoi lettori, a farli pensare; ma non andrebbe mai trascurato che per lui - lockianamente - pensare e sentire sono momenti complementari di un unico processo cognitivo. 